\title{
Agricultural Broadcasting Media (ABM) for Agricultural Developments and Structural Change within and Across the Countries: A Review
}

\author{
Usman Kedir \\ Adami Tulu Agricultural research center, Ziway, Ethiopia
}

\begin{abstract}
Media is a powerful communication tool. The use of media in the field of agricultural marketing offers great opportunities for the buying, selling of agricultural commodities. Agriculture is a vital pillar for sustainable development and poverty reduction; it continues to face challenges and emerging constraints at the global, regional and national levels that require urgent and special attention with the help of media. Broadcasting can be referred as the planned provision of information, education and entertainment to large and heterogeneous audiences through the medium of television. Television has the potential to diffuse development information and supplement the extension effort. The media is an important vehicle through which information can be obtained and exchanged. The emergence of information and knowledge society is a significant intervention with the potential to ensure that both are very important for achieving meaningful development. The scarcity of information on communication channels is a great threat for rural development where majority of the people are illiterate thus, do not know how to access information themselves. The media is critical in shaping public opinion and generating deeper insight into human working. The most important step to prepare the rural people against agricultural development is to create informed communities. Media can play a vital role in informing farmers in the situation of urgency and current development. To agriculture as an industry, the key values of communication that media provides are peer to peer networking, farmer-industry networking, consumer engagement, and crisis communication. Media can play a vital role in informing farmers in the situation of urgency and current development. Hence, media, being source of information and entertainment, can play a vital role to transform attitude and interest.
\end{abstract}

Keywords: agricultural development, information, media

DOI: $10.7176 / \mathrm{NMMC} / 91-01$

Publication date:June 30th 2020

\section{Introduction}

Media is a powerful communication tool. Media play a significant role in any given society, and such it is a significant force in modern culture. Agriculture is a vital pillar for sustainable development and poverty reduction; it continues to face challenges and emerging constraints at the global, regional and national levels that require urgent and special attention with the help of media. Broadcasting can be referred as the planned provision of information, education and entertainment to large and heterogeneous audiences through the medium of television (Folarin, 2000). The electronic media through broadcast economic programmes can help in educating the masses and can also contribute directly to the national development, through accelerating and easing the long, slow social transformation required for social-economic development (Onabanjo 2000).

Broadcasting aid national development, it fosters the economic growth of any developed and developing countries. It is crucial for development purpose within a society both on the urban and rural communities. Ethiopia has adopted a national economic policy that mainly focuses on implementing the Agricultural Development Led Industrialization (ADLI). The objectives of ADLI include promotion of economic efficiency and growth, development of domestic technological capacities and capabilities for the promotion and development of small, intermediate and capital goods industries (Anonymous, 2010). Soola (2002) reported that "development implies a change for the better, the ordering of society and social and economic process in such a way as to lead to eradication of gross poverty, ill-health, and increased material standards of living and increased material comforts for all".

According to Udoakah (1998), development communication is about how communication can be used for organized development, it is an attempt to influence the public to accept new ideas, to win citizens for new ways of doing things. Development communication is therefore corrective, integrative and revolutionary in nature and it is result oriented. The need for development communications continues since a large population lives in rural areas and depends directly on agriculture. Therefore, communication and media are essential for development oriented change to occur in any society. Communication provides to the human dimensions of development; it establishes a dialogue with rural people, involves them in the planning of their own development, provides information as a basis for social change and conveys the knowledge and skills required to improve the quality of their life. Okiy (2003) state that, rural development is a basis for economic development and information is an important ingredient in development process, people in rural areas whether literate or not should have access to any kind of information which will help them to become capable and productive in their social and political 
obligations, to become better informed citizens. There is therefore a need for media to broadcast economic programmes especially programmes on agriculture; because agriculture is perceived as an economic bridge between rural and urban areas; and agriculture provides food, work and natural resource services to urban dwellers.

Broadcast programming involves articulation and strategic selection of programmes for desire purpose ends, functional programmes mix, appropriate scheduling, good timing, targeting, "catching" functional or result oriented presentation of programmes on television. The broadcast economic programmes objectives should monitor trends and developments in production process with a view to arousing creativity and inquisitiveness in the people, foster the spirit of hard work and high productivity with the raising quality of life of the society, and encourage the production and consumption of local products in order to continue self-sufficiency and self-reliance (Onabanjo, 2001). A study was conducted to know the role of electronic media in the adoption of agricultural technologies by farmers in the central punjab-pakistan ( Mazher et al.,2003). The result showed that $67 \%$ farmers had radio and television sets. However, more than $56 \%$ farmers of the study area listened/watched agricultural programs on radio and television, respectively.

Whether it is realized or not the agriculture sector remains as one of the relevant sectors in many countries and its significant role in uplifting the economy of a nation cannot be argued(Hassan et al., 2010). The emergence of information and knowledge society is a significant intervention with the potential to ensure that both are very important for achieving meaningful development. Different subject matter specialists can come up with excellent agriculture programs/projects, but these interventions cannot succeed if they have not been properly communicated to the end user (the farmer) and other key stakeholders. The scarcity of information on communication channels is a great threat for rural development where majority of the people are illiterate thus, do not know how to access information themselves. In order to use full effect of global changes, politics of agricultural products pricing, marketing and trade; agricultural media must be revisited.

It is called as today's world is world of 'Social Media'. Society has become thoroughly mediatised. Every aspect and area from the economy and politics to civil society and everyday social relations are increasingly saturated, in ever new ways, by media. So that it is important the agriculturists explore communication options such as Media. Using media for new information is important to reach end users very fast in order to use potential opportunities and achieve benefits. Media allows users to communicate directly with the customers, service providers; information sharing centers etc. Information that disseminates though media is necessary condition for improvement of all areas of agriculture's. Television is acknowledged as the most important medium for communicating with the rural population of developing countries.

Television has the potential to diffuse development information and supplement the extension effort (Rao, 1992). Information needs of farmers vary because the intended purposes for them are many. Information on seed, fertilizer, water, nutrients and plant protection is one of the main factors for successful farming. The use of social media in the field of agricultural marketing offers great opportunities for the buying, selling of agricultural commodities. Chisenga, Entsua-Mensah and Sam (2007) pointed that small-scale poultry farmers were actively seeking information on local available markets, prices for local poultry and poultry products, and information on imported products, mainly to be used in the strategic approach to the conduct of their business. Meitei and Devi (2009) established that farmers also need other types of information like health, education and training. Such information complements each other in agricultural development.

Media information's are directly related to the socioeconomic development of every country. A main benefit of media in agricultural marketing is ability to gain wealth of knowledge and ideas, opportunity to establish key partnership, opportunity to reach wider consumers, experts in agricultural field. Wisely use of Agricultural broadcasting media has power to disseminate the valuable agricultural information to the farmers and other officers. Yakubu and Usman (2012) contend that television are considered as the major sources of information in the rural populace and are the main communicating tools for disseminating agricultural information to the farmers, highly relevant to farmers and normally applied by them in solving their problems.

To further develop and strengthen the relevance of agriculture to this country, the role of media can be one of the main catalysts. Musa (2008) emphasizing that farmers prefer to use traditional mass media such as television and radio compared to internet. On television agriculture information easily understandable because they clarify it, on newspaper the agriculture information sometimes cannot be understandable to all peoples equally. Because of one visuals dissemination of information's reach millions of people per days and changes thousands of people per days. Therefore Building agricultural media is very important.

As mentioned above, this paper aims to give a theoretical contribution of media role in agriculture and potential in providing of information support to the agricultural sector with specific focus on increasing agricultural production and economic benefits of farmer's thorough improving agriculture with media. In order to meet this aim practically, the paper is structured in six main parts or Objectives.

1) Building Agricultural Broadcasting Media (ABM) station in Ethiopia

2) To develop and commercialize knowledge and technologies;

3) To strengthen people for technology accumulation and transfer; 
4) Connecting agriculture and industries with each other

5) To strengthen the interdisciplinary exchange and cooperation within the relevant fields of research.

6) Dissemination of the content of international forum, federal and regional annual review information in different Ethiopians and world languages to reach people within short time.

\section{Importance of media for agriculture}

The media is an important vehicle through which information can be obtained and exchanged. Indeed nowadays public knowledge about foreign events, including war and international crises, relies heavily on mass media. As the so-called 'fourth estate', the media is also a powerful tool in influencing public opinion and raising awareness about an issue. With such power, however, comes also the responsibility to provide accurate information to the public on a given issue and at the same time to ensure the protection of individual sources from any harm as a result of information disclosure.

Media blends technology and social interaction. Media gives farmers and rural businesses a voice and provides invaluable networking opportunities for continuous two-way communication. The media often creates or reinforces stereotypical and negative images about people. One should promote the media as a useful vehicle to spread awareness and understanding of human activities while at the same time advocating for a socially responsible journalism. The media is critical in shaping public opinion and generating deeper insight into human working. Responsible journalism provides accurate information on a given issue to the public and ensures the protection of individuals from harm as a result of information disclosure. Due to the familiar format, content and the usage of local language, traditional media has clarity in communication. Media have extended the area of coverage of a traditional performance. Media can be very helpful in knowledge management for rural users. Positive attitude towards media is important for using it and this needs increased awareness and training programs.

\section{The importance of media to improve agricultural development}

Within a few years, media has ability to completely changed communication globally, forcing enterprises and development agencies to take notice. Social media has already impacted the wind of global development making people more informed and aware. Its introduction for agvocacy is still very recent but the promises it is showing are huge. Agvocacy is the combination of two words agriculture and advocacy and means talking for and about agriculture. It is about the representatives of agriculture proactively telling their story. The term was coined by Mike Haley, a grain farmer and cattle rancher from Ohio (AgChat Foundation, 2014). Social media gives an opportunity to connect and interact with one's audience in agriculture, educate them and helps to know more about the industry. It makes promotion of extension programs easier, allows real time interaction with clients, helps extend outreach to new audiences, and promotes development of relationship among actors in Agricultural Innovation Systems (AIS) (Cornelisse et al., 2011).

The extensionists or extension organizations can start by making an effective social media page, getting followers to collaborate for practical actions on the information shared through the social media pages, and keep the followers involved by continuous engagement through conversations to form a mutually created knowledge pool (Typhina et al., 2015). The most important step to prepare the rural people against agricultural development is to create informed communities. Success in agriculture and rural development is determined by action of millions of rural families on an individual basis whose decisions are shaped by the information, knowledge and technologies available to them (FAOb, 2015) and Information and Communication Technologies (ICTs) can provide new opportunities in fostering innovation, facilitating communication, and innovation brokering by AEAS organizations. Media is a platform of engagement where agriculture is the content and for agricultural producers, the major reason for using these platforms is mass influence (Varner, 2012). It gives farmers a voice and an opportunity to directly connect with their customers, which can help in direct marketing and increased profits alongside facilitating mass-personal communication (Carr and Hayes, 2015). Also, they don't need to depend on a single source for information anymore and with increased contact with peers, tried and tested information at the right time can prove to be a very important input.

To agriculture as an industry, the key values of communication that media provides are peer to peer networking, farmer-industry networking, consumer engagement, and crisis communication (Stanley, 2013). Media provides agribusinesses and agripreneurs a never before opportunity to connect with consumers and build relationships. Media presence also increases the online visibility of extension websites (Arnold et al., 2012) which is another big advantage for quicker information dissemination. For researchers and academicians, creating peer networks are an important part of career advancement as well as dissemination of important findings that can be translated on farms and media provides a very good platform for academic and professional networking. In a nut shell, media has huge opportunities and incentives for all the stakeholders in agricultural sector but more importantly, in the age of pluralistic extension, it is an excellent platform for making all the actors a part of the greater agricultural community.

Media use has more to do with mindset than with age. While many farmers across the globe are taking to 
social media to connect with experts and their peers, extensionists and extension organizations are much laid back by stereotyping farmers and believing they are not technologically savvy (Diem et al., 2011; Payn-Knoper, 2013). Also, there is the question of social media etiquette. Maintaining professionalism on social media is very important, especially when affiliated to professional organizations as online behaviour of individuals may reflect upon one's organization. There are both advantages and disadvantages of "friending one's clientele" (Hill, 2014) and extensionists and other professionals need to remember the do's and don'ts of social media behaviour to successfully communicate with target audiences (Harder et al., 2011).

\section{Impact of media on nutrition information of food choice (Media Impact of Nutrition Information on Food Choice)}

New nutritional information, and its connection with food, is expected to affect consumers' food choices by reducing uncertainty about the health attributes of those foods. Understanding the impact of nutritional and health information on consumers' food choices will contribute to the development of economic models of consumer demand and to the development and implementation of effective communication approaches for changing dietary behaviors. The media are a principal source of information about food and nutrition for many people (American Dietetic Association, 1997). In addition, the media have the capacity to persuade. Research documenting coverage of an issue and consumer response (i.e., decreased consumption or increased sales) has demonstrated the powerful influence of the media in our society (Levy, 1987 and Foerster, 1997). Even though new information initially becomes available to the public in scientific journals, they are unlikely to be a direct information source for most consumers. Moreover, consumers tend to get the information through public media rather than from doctors or dietitians (Food Marketing Institute, 2008). Nutritional information on food labels can guide people in making decisions about healthy food choices. Thinking critically about how food choices can have an impact on whether the choices are as healthy as possible. Advertising and media use a variety of tactics that target children or youth and can influence food choices. Therefore scientific nutritional information and knowledge on consumer demand will be presented by the mass media.

\section{The role of media in Ethiopia on agriculture}

Nothing seems more important in agricultural development than the dissemination of latest agricultural technologies among farmers. Media can play a vital role in informing farmers in the situation of urgency and current development. Farmers can be informed quickly and swiftly about diseases and pest control, flood, and changing weather (Muhammad, 2005). Farmers can also get appropriate advices of experts through these media to cope up with the emerging problems (Albarran, 2002). For dissemination of Agricultural technologies various methods/media are being employed by the extension wing involving both interpersonal and impersonal contacts (Muhammad, 2005). Various extension methods are useful in various situations and the selection of the most appropriate method is the key function of the extension agent (Nisha, 2006; Okunade, 2007). Among various extension methods, use of media is useful in creating awareness and stimulates interest, along with large coverage of the audience (Hussain, 1997; Okunade, 2007). In this era of information revolution, the use of electronic media seems inevitable to accomplish the task of Agricultural technology transfer on account of coverage and speed. Media, being source of information and entertainment, can play a vital role to transform attitude and interest.

\section{Methodology}

It is the responsibility of journalists to critically examine, evaluate and report the relevance of a development project to national and local needs, the difference between a planned scheme and its actual implementation, the difference between its impact on people as claimed by the government and as it actually happened. So development journalism "is not reporting about events, but processes, and not reporting about personalities but issues."

\section{Theoretical framework}

The study will be grounded in the Agenda setting theory, Developmental media theory and Uses and gratification theory.

\section{Agenda setting theory}

The term "agenda-setting was coined by Mac Comb's and Shaw (1972-1993) and focuses on the ability of the mass media to direct attention to certain issues to make them inevitable for public discussion (Aina 2003). The media will provide the society with what to think and how to think about them. In relation to the role of media in fostering development in the society, the media set agenda for important topics by creating awareness and diffusing a personal value system favorable for innovation.

\section{Developmental media theory}

The development media theory arose for events in developing nations (Mac Quail 2005). The major rules of development media theory opined by Mac Quail (2005) are:

- Media must accept and carry out positive development tasks in line with naturally establishment policy.

- Freedom of the media should be opened to economic priorities and development needs of the society. 
- Media should give priority in the content to the national culture and language.

Journalists and other media workers will have the responsibility as well as freedom in their information gathering and dissemination tasks in the interests of development purpose by speaking the language of the people and promoting the interests of the people.

Uses and gratification theory

The last theory applied to this study will be uses and gratification theory; which is the idea that media use depends on the personal satisfactions, need wishes, or motions of the prospective audience member is almost as old as media research itself (Mac Quail 2005). Folarin (2005) further says the theory perceives the recipient as actively influencing the effect process, since he selectively chooses, attends to, perceives and retains the media messages on the basis of his/her needs, beliefs etc.

Conceptual clarification

Development communication: the use of communication to promote social development

Economic programmes: programmes that will provide information and education on economic issues like development in different areas of agriculture.

\section{Implementation}

The programme will aim to strengthen interdisciplinary exchange and cooperation within the relevant fields of research. Its themes tie in with the research interests of different research councils.

\section{Community participation and empowerment}

The strength of media is its ability to widely reach illiterate farmers and provide them with information relating to all aspects of agricultural production in a language they understand. This does not mean simply reading technical information over the airwaves in local languages, but understanding the way farmers themselves discuss their problems in the community and providing relevant information in the local agro ecological and cultural context. Extension services have been criticized both for failing to reach the majority of farmers in many developing countries and to communicate successfully with those that fall within range.

\section{Better Media strategy}

To build a better Media strategy

1. Stay consistent

Consistency breeds trust and trust breeds relationship

2. Stay current

Keep up-to-date on all market trade and technology

3. Stay relevant

Share topical information that keeps you in the forefront of the consumers mind

\section{Summary and conclusions}

The Ethiopian government is keen to establish Agricultural Broadcasting Media (ABM) as soon as possible, in order to derive agricultural development and structural change for the country and benefit for citizens. The plan is ambitious but the Government is determined to meet this. With indicative timeline it is important to build on good planned time set.

\section{References}

AgChat Foundation. 2014. Foundation Q and A. http://agchat.org/ about/foundation-qa (Accessed on 21.12.2018). Albarran, A.B. 2002. Management of Electronic Media (2nd Ed.). Wadsworth, Thomson Learning, USA. American Dietetic Association. 1997. Nutrition trends survey. Chicago IL. American Dietetic Association. Anonymous. 2010. The Federal Democratic Republic of Ethiopia National Science, Technology and Innovation Policy: Building Competitiveness through Innovation, Addis Ababa.

Chisenga, J. Entsua-Mensah, C. and Sam, J. 2007. Impact of Globalization on the Information Needs of farmers in Ghana: A Case Study of Small-Scale Poultry Farmers. Paper presented at 73rd IFLA General Conference and Council 19-23 August 2007.

Cornelisse, S., Hyde, J., Raines, C., Kelley, K., Ollendyke, D., and Remcheck, J. 2011. Entrepreneurial Extension conducted via social media. Journal of Extension, 49(6).

Carr, C. T., and Hayes, R. A. 2015. Social media: Defining, developing, and divining. Atlantic Journal of Communication, 23(1).

Diem, K.G., Hino, J., Martin, D. and Meisenbach, T. 2011. Is extension ready to adopt technology for delivering programs and reaching new audiences? Journal of Extension, Article number FEA1, 49(6).

FAO(b). 2015. Research and Extension. http://www.fao.org/ nr/research-extension-systems/res-home/en/ Accessed August 08, 2015.

Foerster S. 1997. California dietary practices survey: focus on fruits and vegetables, trends among adult 1989-1995. Sacramento CA. California Department of Health Services. 
Food Marketing Institute, 2008. U.S. Grocery Shopper Trends.

Folarin, B. 2000. Foundation of broadcasting. Ibadan: secreprint Nigeria limited.

Hassan, S., Azril, H., Shaffril, M., Sham, M., and Ali, S. 2010. Agriculture agency , mass media and farmers : A combination for creating knowledgeable agriculture community. African Journal of Agricultural Research, 5(24):3500-3513.

Harder, A., Carter, H.S. and Chiarelli, C. 2011. Maintaining professionalism on Facebook: Tips for extension agents. WC107, Agricultural Education and Communication Department, Florida Cooperative Extension Service, Institute of Food and Agricultural Sciences, University of Florida.

Hill, P. 2014. "Connecting” with your clients \{on Facebook\}. Journal of Extensio, 52(2).

Hussain, M. 1997. Mass media. In: Memon, R.A. and E. Bashir (Eds.) Extension Methods. National Book Foundation, Islamabad. pp. 209-261.

Levy A, Schucker R. 1987. Patterns of nutrient intake among dietary supplement users: attitudinal and behavioral correlations. J Am Diet Assoc., 87:754-60.

Mazher Abbas, A.D. Sheikh, Sher Muhammad and Muhammad Ashfaq. 2003. Role of electronic media in the adoption of agricultural technologies by farmers in the central Punjab-Pakistan. International journal of agriculture and Biology, 5(1):22-25.

Meitei, L. S. and Devi, T. P. 2009. Farmer information needs in rural Manipur: an assessment. In Annals of Library and Information Studies, 56:33-40.

Mucavele, Firmino G. 2009. True contribution of agriculture to economic growth and poverty reduction: Malawi, Mozambique and Zambia Synthesis Report.

Muhammad, S. 2005. Agricultural Extension: Strategies and Skills. Unitech Communications, Faisalabad, Pakistan.

Musa AH .2008. Benefiting information and communication technology for all. Inaugural Lecture Series. Selangor, Universiti Putra Malaysia Publisher.

Nazri, Mohammad Reza. 2012. Role of Broadcast Media in the Dissemination of Agricultural Knowledge. Archives Des Science, 65(3).

Nisha, M. 2006. Understanding Extension Education. Kalpaz Publications, Delhi.

Okiy, R.B. 2003. Information for rural development: challenge for Nigerian public libraries. Library Review, 52(3).

Okunade, E.O. 2007. Effectiveness of extension teaching methods in acquiring knowledge, skill and attitude by women farmers in Osun state. J. Appl.Sci. Res., 3(4):282-286.

Onabajo, O. 2000. Principles of Educational Broadcasting. Lagos: Gabi Concept limited.

Onabajo, O. 2001. Broadcast Management and Programming. Lagos: Gabi Concept limited.

Payn-Knoper, M. 2013. No more food fights! Growing a productive farm and food conversation. Dog Ear Publishing, Indianapolis.

Rao, B.S.S. 1992. Television for rural development. New Delhi: concept publishing company.

Soola, E. O. 2002. Development Communication: The past, the Present and the future. In Soola, E.O (Eds). Communication for Development Purposes. Oyo: Kraft Books Limited.

Typhina, E., Bardon, R.E., and Gharis, L.W. 2015. Collaborating with your clients using social media and mobile communications. Journal of Extension, 53(1).

Uduakah, N. 1998. Development Communication. Ibadan: Stirling-Horden Publishers (Nig) Ltd.

Varner, J. 2012. Agriculture and social media. Mississippi State University Extension Service, Mississippi, USA.

Yakubu, D. H. and Usman A. 2012. Farmers' perceptions on the role of mass media in sustainable agricultural development: A case study of the Northern Zone of Sokoto Agricultural Development Project (S.A.D.P.), Nigeria. Journal of Agticullture and Biological Sciences, 3(3):305-312. 